\title{
V15 - MODELO PARA AVALIAÇÃO DE RISCOS DE PROCESSOS PRODUTIVOS PROVENIENTES DE TRANSFERÊNCIA DE TECNOLOGIA APLICADO A VACINA ROTAVÍRUS HUMANO G1P1[8] (ATENUADA)
}

$\underline{\text { Lívia Rubatino de Faria }}{ }^{1}$, Antonio de Pádua Risolia Barbosa ${ }^{2}$, Marília Stella Vaz Costa Belart $^{1}$

1. Bio-Manguinhos, Fundação Oswaldo Cruz, Departamento de Garantia da Qualidade, Rio de Janeiro, Brasil

2. Bio-Manguinhos, Fundação Oswaldo Cruz, Vice-Diretoria de Produção, Rio de Janeiro, Brasil

Objetivo: Este estudo de caso tem como objetivo realizar a avaliação de riscos dos equipamentos e processos produtivos de produtos de Bio-Manguinhos adquiridos por transferência de tecnologia.

Metodologia: Para alcançar o objetivo proposto, utilizou-se a ferramenta FMEA (Failure Mode and Effect Analysis) na avaliação dos riscos das etapas de preparo dos constituintes, descongelamento do insumo farmacêutico ativo (IFA) e de formulação da vacina rotavírus humano G1P1[8] (atenuada). A etapa de envase da vacina em estudo será realizada por máquina de envase específica que teve seu impacto avaliado e seus riscos identificados com a ferramenta HAZOP (Hazard and Operability Study).

Resultados: Como resultados, foram elaborados os fluxogramas das etapas do processo produtivo e foram avaliados, com a ferramenta FMEA, 217 riscos sendo que 147 foram encontrados na etapa de preparo dos constituintes, 33 foram encontrados na etapa de descongelamento do IFA e 37 foram encontrados na etapa de formulação. Também foi realizada a avaliação do impacto e a identificação dos riscos da máquina envasadora utilizando a ferramenta HAZOP.

Conclusão: Nas etapas de preparo dos constituintes, de descongelamento do IFA e de formulação da vacina rotavírus humano G1P1[8] (atenuada), a aplicação da ferramenta FMEA se mostrou bem sucedida, demonstrando que a mesma pode ser aplicada em processos de transferência de tecnologia. Em relação à máquina envasadora, a avaliação de impacto não foi capaz de selecionar os componentes mais críticos, visto que todas as partes, segundo o método proposto, alcançaram a mesma classificação. Na identificação 
dos riscos deste equipamento, a ferramenta HAZOP foi bem sucedida, mas as informações necessitarão de aprofundamento e revisão conforme avanço da transferência de tecnologia. 